\title{
ARTE CONTEMPORANEO Y PARTICIPACIÓN: LA REFLEXIÓN Y EL DIÁLOGO COMO GENERADORES DE DISTRACCIÓN POSITIVA ${ }^{1}$
}

\section{Contemporary Art and participation: Reflexion and dialogue for creating positive distraction}

\author{
Marta G. CAno. \\ Universidad de Complutense de Madrid. \\ martag02@pdi.ucm.es
}

Recibido: 18 de Mayo de 2011

Aprobado: 13 de Junio de 2011

\begin{abstract}
Resumen:
La realidad de la socialiación en el contexto hospitalario se ve muy restringida. La mayor parte de las relaciones giran en torno a la enfermedad. En este articulo se describen las experiencias llevadas a cabo en las habitaciones de oncología Infantil y la sala de tratamiento de diálisis en el Hospital Gregorio Marañón de Madrid. Proyectar imágenes sobre las paredes se presenta como una intervención que facilita la participación de quienes se encuentran ahí y genera dinámicas y diálogos que se traducen en otra forma de relacionarse más allá de la enfermedad. Dos contextos diferentes en los que una misma acción, proyectar, deriva no sólo en un momento de distracción, tambien en una oportunidad educativa y relacional. Ambas experiencias han servido como antecedente para inciar un proyecto más ambicioso, la creación de un espacio en el que pacientes, familiares y personal sanitario puedan ser dueños del espacio que ocupan a través de diferentes propuestas que desde el ámbito del arte contempóraneo les son ofrecidas en busca de su participación y colaboración, facilitando dispositivos que motiven la acción y la elección en un lugar, el hospital, en el que todo está programado. Ellos elegiran compartir, con el arte como excusa, momentos de desconexión y establecer diálogos en torno a su actividad. Este espacio es en la Biblioteca de Pacientes del Hospital Universitario 12 de Octubre de Madrid.
\end{abstract}

Palabras Clave: Arte Contemporáneo, participación, proyección, contexto hospitalario.

G. Cano, Marta (2011). Arte Contemporáneo y participación: la reflexión y el diálogo como generadores de distracción positiva. Arte, Individuo y Sociedad, Vol. 23, Núm. Especial, 109-122.

\begin{abstract}
:
So We could say that social relationships in hospital are very restrictive. They are always around illness. This article try to describe two different experiences taken place in Children Oncological room and Dialysis treatment room in Hospital Gregorio Marañon in Madrid. In both places we have projected Contemporary Art images on the walls. So with this action, we have tried to bring up participation and new dialogues in order to make possible other dialogues, and avoid illness item for a while to make people participate and socialize.The same action, projecting images, turns not only a temporary positive distraction but and education and relational chance.Both experiences have been a precedent for a bigger and more ambitious project which is to create a place where patients, companions and sanitary staff could share conversation, participate and socialize in order to disconnect from hospital and illness
\end{abstract}

\footnotetext{
${ }^{1}$ Esta investigación ha sido financiada por el Ministerio de Ciencia e Innovación (EDU2008 05441-C02-00/EDU)
} 
around cultural event. This is taken place at Patient Library in Hospital Universitario 12 de Octubre in Madrid.

Key words: Contemporary Art, participatión proyection, hospital context.

Sumario: 1. Introducción 2. Contexto. 3. Antecedentes: La imagen en el contexto hospitalario. 4. Los talleres. 5. Talleres en diálisis. 6. Talleres en oncología. 7. Conclusiones. 8. Un nuevo proyecto. Referencias

\section{Introducción}

El hospital es un lugar de rutinas, de tiempo, de espera. Un lugar con escasos espacios en los que relacionarse de otra manera, más allá del diálogo de la enfermedad y carente de recursos que generen estímulos para otros diálogos y por tanto para otras imágenes de la vivencia hospitalaria, que nos devuelvan una experiencia más positiva, más cercana a las experiencias posibles fuera del contexto de la enfermedad. La convivencia diaria entre pacientes, acompañantes y personal sanitario, su manera de comunicarse, me planteaba la necesidad de actuar en favor de todos, buscar un tipo de intervención que pudiera ser útil en mayor o menor medida para favorecer una comunicación distinta, esas otras imágenes. Todo ello, además, desde el Arte Contemporáneo y desde la experiencia que el Departamento de Didáctica de la Expresión Plástica de la Facultad de Bellas Artes de la UCM, el Museo Pedagógico de Arte Infantíl y el Proyecto Curarte I+D, a los cuales pertenezco, tienen dentro del ámbito Arte en contextos de Salud.

Por otra parte, ya que mi principal preocupación se había centrado en la comunicación, en los diálogos y conversaciones enclaustrados en el tema de la enfermedad y el hospital, también parecía lógico a la hora de actuar hacerlo en aquellos lugares donde hubiera un mayor aislamiento o una menor posibilidad de movimiento, de pacientes y familiares a los que llamaré "habitantes del espacio interior". La idea se plasmó en realizar intervenciones en los espacios a través de la proyección de imágenes de Arte Contemporáneo. Imágenes, por otra parte, que difícilmente se pueden ver fuera de los Museos de Arte Contemporáneo y por tanto, imágenes totalmente descontextualizadas. El propósito es que sirvieran de vehículo simbólico entre el arte y las experiencias vitales y cotidianas de cada uno y así favorecer la interacción entre "habitantes del espacio interior". Al mismo tiempo, proyectar sobre una pared supone abrir una ventana a través de la cual observar el mundo que hay fuera, más allá del monótono paisaje, si es que lo hubiera, disponible desde la realidad de las ventanas de las habitaciones, consultas, salas de tratamiento, etc. A lo largo de cinco meses, una vez a la semana, se proyectaron imágenes en dos contextos muy diferentes: Oncología Infantil y Sala de Diálisis con adolescentes, en el Hospital Universitario Gregorio Marañón de Madrid. Una misma acción adquirió sentidos diferentes según el lugar y las personas con las que se trabajó y sobre todo sacó a luz el potencial de este tipo de intervenciones y la importancia que el mediador adquiere en ellas. 


\section{Contexto}

Le elección de los contextos estuvo en función del tipo de relación y convivencia que pacientes, familiares y personal sanitario tienen dentro del hospital, de las carencias de estímulos y la dificultad de movimiento dentro del mismo hospital y por tanto la situación de una mayor restricción de relación social.

\subsection{Diálisis Adolescente}

La diálisis básicamente es un tratamiento que se aplica a enfermos con insuficiencia renal y consiste en limpiar la sangre, es decir, realizar a través de una máquina las funciones que el riñón no realiza. La frecuencia del proceso depende del grado de deterioro del riñón, y oscila entre uno a tres día a la semana, entre tres y cuatro horas por cada sesión. Una de las reacciones más frecuentes en los pacientes que se someten a diálisis, es la de adormecerse durante el tratamiento. Es una forma de evadirse e ignorar en la medida de lo posible el momento, una reacción de rechazo. La apatía, la desilusión, la falta de interés, la dificultad de concentración son características propias de estos pacientes (Arriba Barahona, C. 1987) que se encuentran en parte inmovilizados, enganchados a una máquina que dificulta su movilidad incluso en la cama.

Tipo de paciente. Adolescentes, no internos pero habituales de larga duración por causa del tratamiento, acuden tres veces por semana, $4 / 5$ horas.

Recursos disponibles. Televisión, asistencia educativa. El profesor acude y trabaja con cada uno de ellos de forma individual.

\section{Habitantes del espacio interior. $P$} ñantes ni familiares.
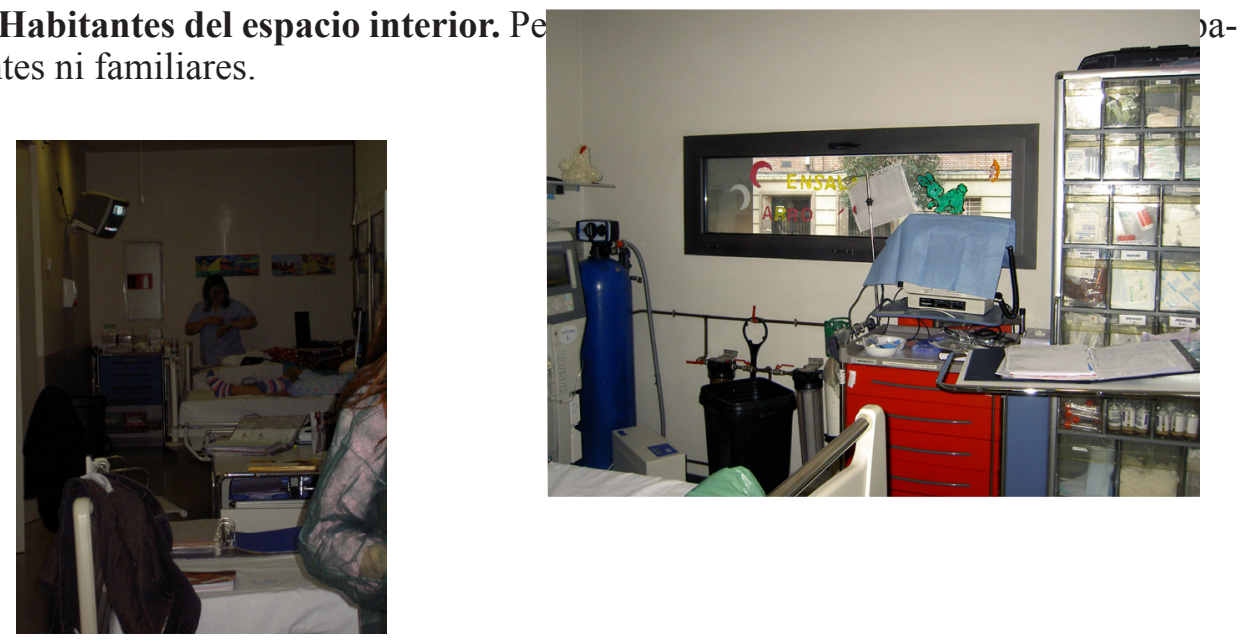

Fig. 1.y 2. Sala de diálisis en el hospital Gregorio Marañón de Madrid. 


\subsection{Oncología infantil}

Tipo de pacientes. Niños oncológicos. Acuden periódicamente al hospital para tratamiento o por otras razones como infecciones etc. Permanecen internos un mínimo de 5 días.

Recursos disponibles: Televisión. Todo tipo de juegos proporcionados por los padres. Si están con ánimo pueden salir a la sala de juegos. No hay recursos específicos para adultos más allá de la televisión.

Habitantes del espacio interior. Acompañantes permanentes (madres por lo general), familiares y personal sanitario fundamentalmente.
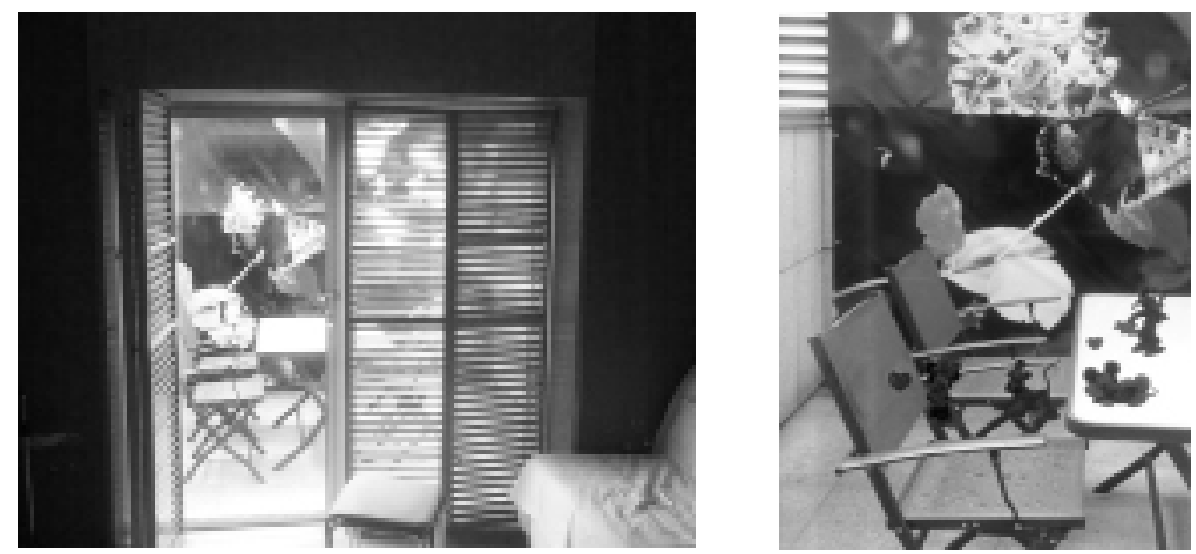

Fig. 3.y 4. Vista de las terrazas disponibles en las habitaciones de oncología infantil en el hospital Gregorio Marañón de Madrid.

\section{Antecedentes. La Imagen En El Contexto Hospitalario}

Trabajar en un contexto de salud supone que cualquier actividad, cualquier intervención que en él se realice tenga su máxima prioridad en el bienestar.

Existe una extensa literatura, acerca de cuáles pueden ser las imágenes más adecuadas para el contexto hospitalario dentro del arte. La mayor parte de los estudios revisados son procedentes de Estados Unidos, pero en estos no se ha contemplado el Arte Contemporáneo específicamente, más bien se han centrado en categorías de estilo y temas dentro corrientes artísticas bien asentadas. En cambio, sí nos hemos encontrado con cuestiones interesantes (Nanda Hathorn y Chanaud \& Brown, 2007) que observaron en los niños una mayor aceptación de las imágenes de la naturaleza que a las clásicas de dibujos animados y fantasía. Y puntualizaciones útiles para nuestros objetivos (Hathorn 1989) que observan ejemplos como que las imágenes de la sabana están asociadas al escape y la soledad por un período de tiempo, sensación que es demandada y que ejerce una emoción positiva en algunos momentos de la hospitalización, pero puede crear sentimiento de soledad a aquellos que la observan 
por un tiempo prolongado. Por último visiones más amplias (Hathorn y Nanda 2008) que contemplan las artes visuales, incluyendo el arte digital y la realidad virtual como forma de distracción positiva para los pacientes, entendiendo por distracción, dirigir la atención a un acontecimiento o estímulo no tóxico para el entorno inmediato.

Por último, señalar que las mayoría de estas investigaciones se realizaron con el sólo propósito de encontrar imágenes adecuadas para encontrar respuestas en los pacientes que las observaban, pero en ninguna de ellas se encuentra la figura de un mediador, educador, guía, que contribuya a enriquecer la experiencia de las imágenes.

Sí existen evidencias, de que el arte, su presencia y la actividad en torno a este en contextos de salud son positivos en numerosos aspectos, siendo uno de ellos el de favorecer la socialización. La actividad cultural dentro del contexto sanitario se presenta como un agente de mejora de la calidad de vida. (Macnaughton, Jane. 2007)

\section{Los Talleres}

\subsection{Planteamiento teórico del taller}

La elección. El ejercicio de elegir supone una reflexión sobre lo que se está viendo, pensar sobre la sensación que nos produce, los elementos que resultan atractivos o incluso lo que cambiaríamos de esa imagen si fuera nuestra, lo que nos sugiere y lo que nos interesa.

En el hospital las oportunidades de elegir son pocas, por tanto elegir las imágenes puede adquirir una especial importancia en este contexto (Suter y Bayling, 2005). Un programa "Art à la Carte" realizado por voluntarios de una ONG de Calgary, Canadá, ofrecía a los pacientes una serie de imágenes previamente seleccionadas. Una vez elegidas, se colgaban en la pared de la habitación del paciente en un lugar donde pudieran verse claramente. Las visitas semanales de los voluntarios permitían cambiar las imágenes siempre que el paciente lo deseara. Entre las conclusiones extraídas, se advirtió el hecho de que poder elegir era identificado como uno de los aspectos al que los entrevistados concedieron mayor importancia.

La elección como propuesta inicial que nos permite entrar en el ámbito de los intereses personales.

Lista de los artistas utilizados en los talleres: Aron Kobblin, Beatriz Millhazes, Carol Bove, Christo, Ellen Kooi, Erwin Wurm, Francis Alys, Gary Hume, Gelitin, David Hockney, Huang Yan, Jim Lambie, Johan Lorbeer, Takashi Murakami, Gabriel Orozco, Susi Gómez, Tobias Reberguer, Virginie Yaseff, Wim Delvoye, Yamashita+Kobayashi, Juan Zamora, Lidia Benavides, Violeta Agudín.

Elegidos atendiendo a las siguientes agrupaciones.

- Imágenes insólitas.

- Naturaleza y paisaje.

- Humor.

- Belleza.

- Color. 


\subsection{Objetivos}

- Establecer otros diálogos.

- Generar un entorno más participativo.

- Familiarizar a los "habitantes del espacio interior" con las imágenes del arte contemporáneo.

- Aportar reflexión y conocimiento.

- Observar qué tipo de imágenes favorecen más nuestros objetivos.

\section{Talleres en diálisis}

En Diálisis los pacientes son habituales, lo que nos permitió establecer pautas de trabajo para obtener una progresión en el mismo y sobre todo para que la actividad fuera atractiva y no se convierta en monótona. Se trabaja en grupos de dos por la disposición de la sala.

Duración: entre 1 hora y 1 hora y media.

Sesiones: 12

a) Elegir la imagen que colgarían en su habitación: Razonar las elecciones en función de sus experiencias. Mostrar imágenes, primero todas seguidas para obtener una idea de lo que van a ver. Despues una a una. El tiempo de permanencia de la imagen lo eligen los participantes en función del interés que suscite esta. Ellos son quienes deben indicar el paso a la siguiente. Preguntas clave: ¿Te gusta?, ¿Por qué? (fig. 5.) "Es muy alegre" (fig.6.) "Me recuerda al campo" (fig.7.) "Simboliza el esfuerzo".

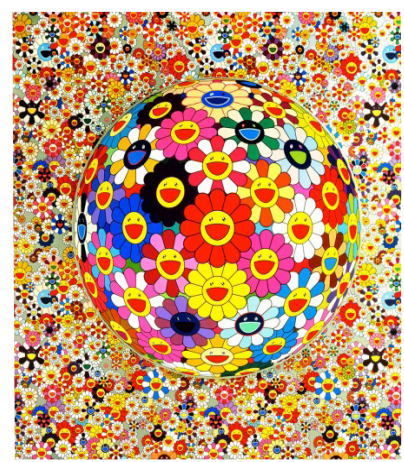

Fig.5. Takashi Murakai

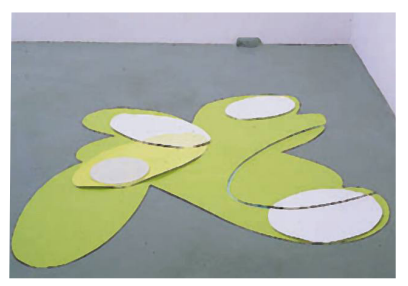

Fig.6. Tobias Reberguer

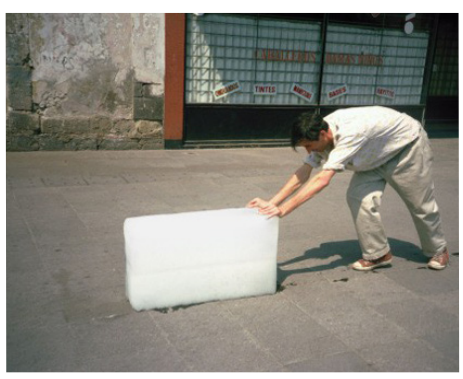

Fig.7. Francis Alys

b) Fotografiar partes de la imagen proyectada que muestren sus preferencias y gustos. Fig.8. "Me gustan las flores". Fig.9. "Me gustan los animales". 


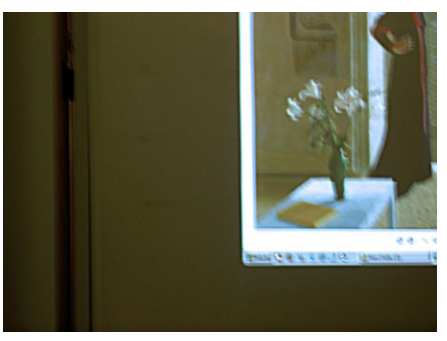

Fig 8. Fotografía realizada por Noelia

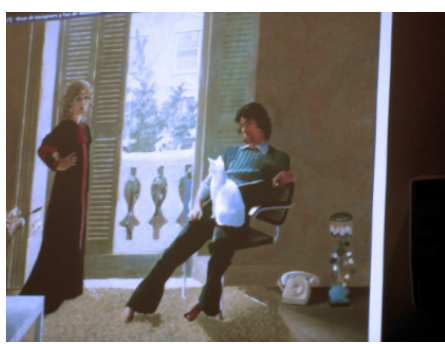

Fig.9. Fotografía realizada por Noelia

c) Fotografiar algo de sí mismas que les gustara Fig.10.

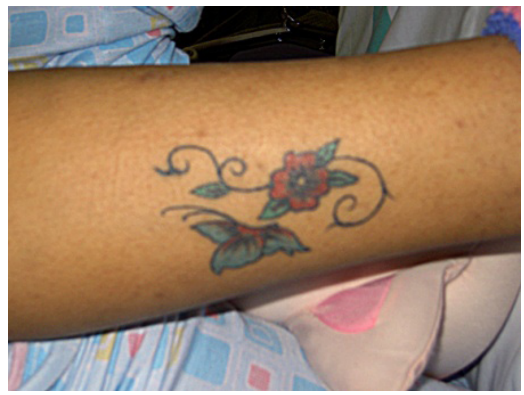

Fig. 10. Tatuaje de Alicia

d) Realizar una puesta en común de lo que nos gusta, no nos gusta y lo que deseamos a nivel personal (fig. 11 y 12). Proyectamos imágenes y en función de lo que nos van sugiriendo se van pegando pos-it en la pared que a su vez interfieren en la imagen. Previamente se ha elegido el color de pos-it que indicará lo que "me gusta" o deseo y el contrario.
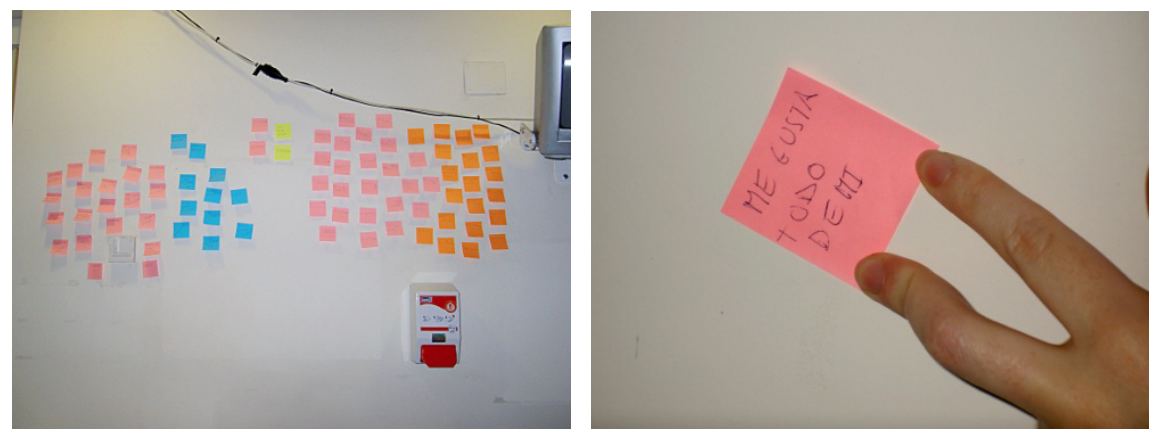

Fig. 11 y 12 Intervención en los cuadros.

e) Modificar los cuadros colgados que no nos gustan (fig.13 y 14). 

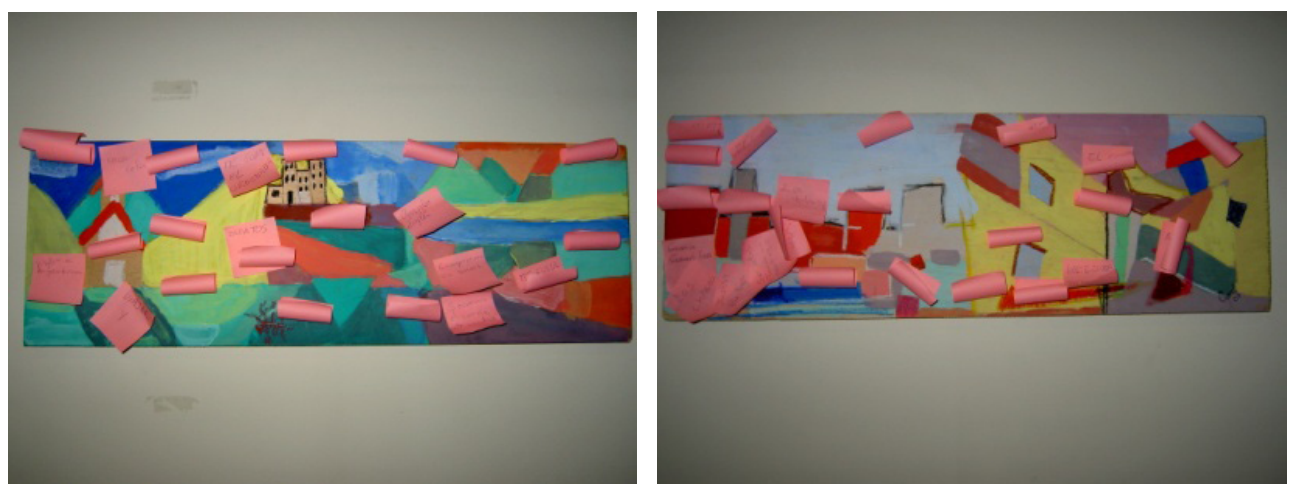

Fig. 13 y 14 Intervención en los cuadros.

f) Realizar una imagen personal con fragmentos de las imágenes revisadas que más nos hayan gustado (fig.15).
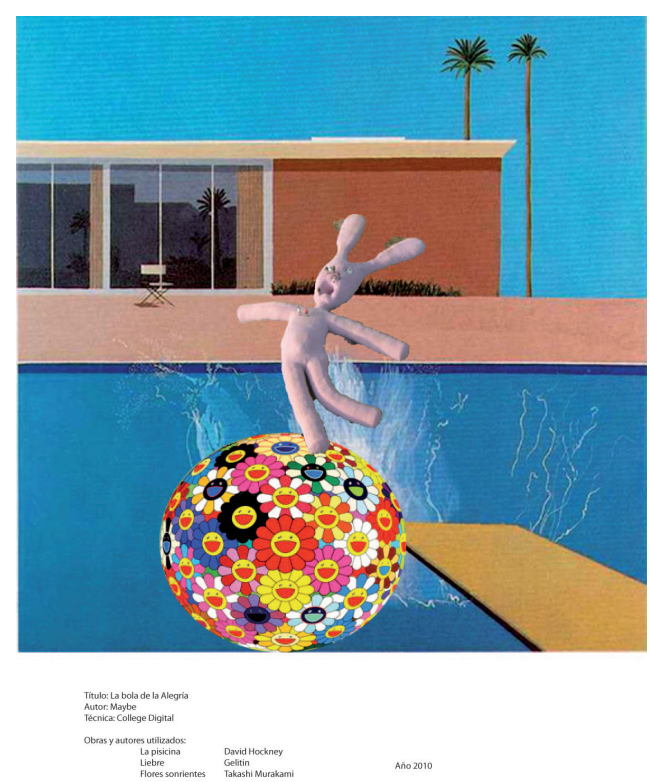

Fig.15. Imagen realizada por Maybe con fragmentos de obras de Hockney, Murakami, y Gelitin.

Durante el proceso se volvió varias veces sobre las imágenes con el fin de constatar las elecciones realizadas tanto en sentido positivo como negativo. 


\section{Talleres en oncología}

Los pacientes no se encuentran de forma permanente, aunque a lo largo de cinco meses sí coincidimos con algunos que quisieron repetir la experiencia.

Período de Trabajo: 5 meses, una vez por semana. Sesiones efectivas de trabajo 10. La edad de los niños oscila entre los 3 y 7 años. Se trabajó siempre con la presencia de los acompañantes, y en ocasiones con dos pacientes y sus respectivos acompañantes a la vez. A lo largo del período de trabajo nos encontramos con 3 adolescentes y ninguno de ellos quiso colaborar.

En este caso la intervención es más espontánea, el acercamiento al niño se produce a través de la madre fundamentalmente.

A los niños se les realizan preguntas sencillas. Es importante dejarles observar la imagen, ver su reacción, ¿Te gusta? ¿Qué ves? ¿Qué pasa? ¿Qué colores son tus favoritos?. Describe la imagen. Los acompañantes participan casi espontáneamente, sin gran esfuerzo por nuestra parte, bien para motivar a los hijos a que participen, bien porque sienten interés. Algunos realizaron sus sugerencias respecto a artistas que podíamos mostrar (fig. 16.).

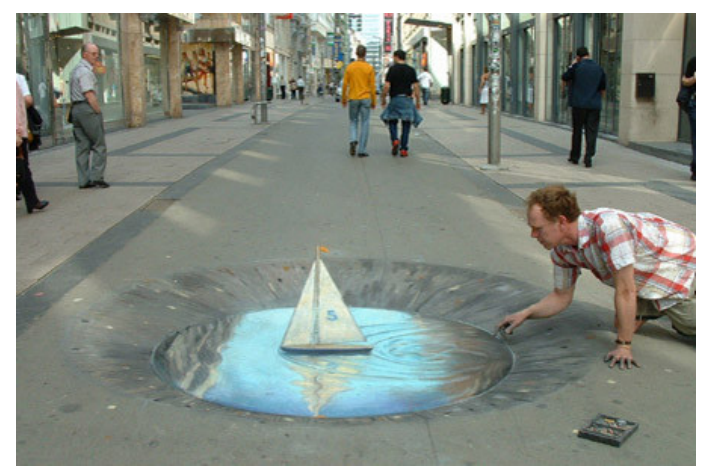

Fig. 16. Julian Beever, artista propuesto por unos padres de niño oncológico.

Durante el tiempo de las sesiones, se producen conversaciones con los acompañantes en los que procuramos obtener información sobre la percepción del espacio, la relación con las imágenes del mismo, qué les parece lo que les estamos haciendo. En cuanto a los niños, para todos resulta un juego. Los más animados se levantan de la cama y hablan de las imágenes interponiéndose entre la pared y el proyector, podríamos decir, que introduciéndose en ella.

Para determinar si realmente las imágenes les gustaban a los niños les preguntábamos si querían verlas otra vez. Tomamos nota del tiempo que se entretenían con cada imagen, de la expresión de su cara, y en las ocasiones que pudimos repetir sesión con ellos les pedimos que nos contaran de qué imágenes se acordaban.

El trabajo se simultaneaba con los acompañantes, madres en su mayoría, con las que desarrollaban temas de conversación paralelos en torno a la tranquilidad, la alegría y demás emociones que encontraban en las imágenes, que se iban trasladando a la puesta en común de experiencias cotidianas. 
En términos generales manifestaron gran placer en la contemplación de paisajes, si bien aquellas imágenes que les resultaban extrañas generaron conversaciones más interesantes y prolongadas, alejadas de la valoración de los estados de ánimo.

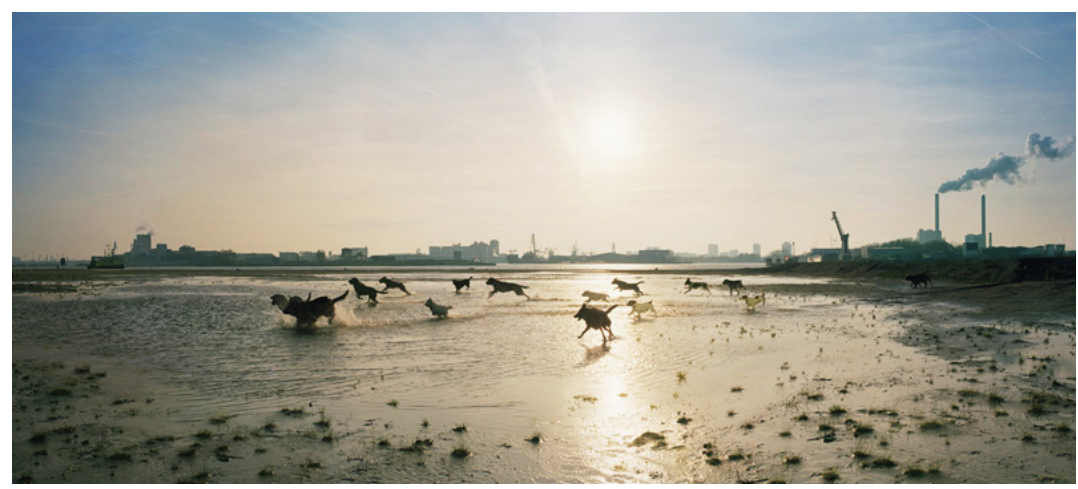

Fig. 17. Ellen Koi

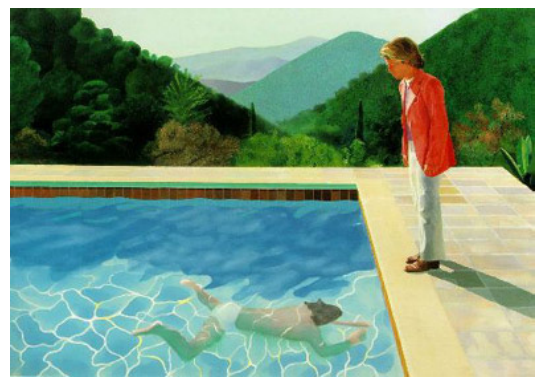

Fig. 18. David Hockney.

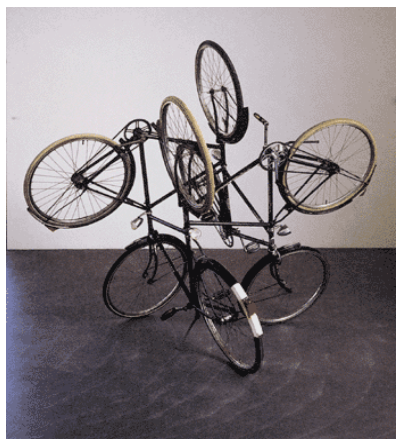

Fig. 19. Gabriel Orozco. 


\section{Conclusiones}

La proyección resulta un medio atractivo para trabajar y estimular la participación de todos. En el caso de los adultos, es difícil plantearles talleres que requieran habilidades manuales, especialmente si la actividad no va a tener una continuidad que en cierto modo asegure un aprendizaje o adquisición de habilidad. Por lo que observar y comentar las imágenes fue aceptado con naturalidad y resultó no solo un elemento de distracción, también de motivación y aprendizaje sobre las maneras de expresión, la imagen y su significado, los vínculos emocionales que se tienen con las imágenes y la posibilidad de reasignar significados a estas.

En el caso de Diálisis, la posibilidad de trabajar con continuidad hizo que la actividad fuera más enriquecedora. Aun así, en este caso fue difícil estimular diálogos fluidos, se mostraron, receptivos pero no muy activos. La enfermeras afirmaban que el puro hecho de que prestaran atención y dejaran a un lado la televisión ya era un logro y en el proceso nos dimos cuenta de la necesidad de observar el lenguaje no verbal, las señales. Los participantes reflexionaron sobre las maneras de modificar y sentir el espacio en el que se encontraban, pero sobre todo reflexionaron sobre lo que supone la elección y el deseo y fueron capaces de ponerlo en común. El personal sanitario de la sala se acercaba con frecuencia y hacía pequeños comentarios, exclamaciones positivas y de admiración. Las pacientes trabajaron de manera sencilla con las imágenes realizando collages con PHOTOSHOP, de esta manera se pusieron también en contacto con programas de diseño profesional y además pudieron compartir el proceso con el personal de la sala, ya que todo el trabajo se realizaba con el proyector en marcha y mostrando el proceso.

En el caso de las madres de los niños de Oncología que participaron de la actividad, manifestaron expresamente la conveniencia de poder realizar una actividad totalmente distinta a la habitual. El hecho de enfrentarse a imágenes distintas propiciaba "hablar de otras cosas", entablar otro tipo de conversaciones y evocar sensaciones que les resultaban agradables.

"Cuando iba a trabajar siempre veía la fábrica a lo lejos, iqué sensación de libertad!". (fig.17.)

"en Verano siempre vamos a la finca de mi hermano a las afueras de Granada, allí juega con sus primos y se lo pasa muy bien. Si le dan el alta este fin de semana a lo mejor vamos". (fig.18.)

"Objetos extraños para construir. Es curioso" (fig.19.).

Fue interesante observar cómo todos aquellos que entraban en la habitación establecían el contacto a través de la imagen que se estaba proyectando. Este aspecto contribuye al enriquecimiento de la experiencia.

La receptividad de los niños al juego con las imágenes fue muy positiva, en cualquier caso la presencia y la actuación de quien modera la actividad es fundamental y considerada imprescindible especialmente por las madres.

En cuanto a la preferencia por las imágenes, en términos generales podemos decir que son válidas todas aquellas que no sean tóxicas para el ambiente, es decir, que no tengan componentes que desde el sentido común nos digan que pueden ser rechaza- 
das en el contexto de la enfermedad. Las que más incitaban al diálogo y la reflexión fueron aquellas que resultaban menos usuales y no se podían calificar de bellas.

El paradigma de la imagen de la felicidad fue la de Murakami, todos sentían una gran alegría ante la presencia de la imagen. Pero más allá de la sensación inicial la imagen no suscitaba mucho más interés, salvo en los más pequeños. (fig.20.)

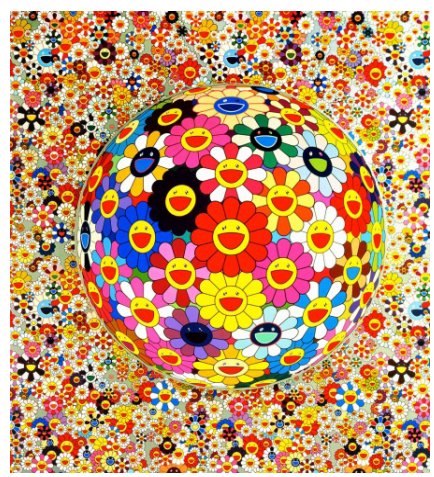

Fig.20. Tashki Murakami.

\section{Un nuevo proyecto en marcha}

El resultado de ambas experiencias ha servido como antecedente para el proyecto que actualmente se está llevando a cabo en el Hospital Universitario 12 de Octubre de Madrid.

El servicio de atención al paciente de dicho hospital nos pidió realizar algún tipo de acción en la Biblioteca de pacientes. Aprovechando el espacio relativamente pequeño de que dispone, se está llevando a cabo la implementación de actividades en torno a exposiciones de arte contemporáneo, utilizando la proyección de imágenes. Además de, como artista, crear obras espécificas, que modifiquen el espacio e inviten a la participación, a lo relacional (Bourriaud, 2007).

El objetivo es generar un espacio cultural en el que el que pacientes y acompañantes puedan encontrar un tiempo de desconexión a través de actividades que generen no sólo distracción positiva, también conocimiento y otra forma de entender el espacio. Hacer del hospital un lugar de oportunidad cultural y de conexión con el exterior, generando dinámicas de normalización que suponen un puente entre las oportunidades de fuera y de dentro del hospital.

Las exposiciones se realizan atendiendo a los mismos criterios que supone la realización de cualquier exposición en un museo, ejerciendo labores de comisariado, difusión y educación.

La primera actividad que se ha puesto en marcha es la que parte directamente de la experiencia de oncología y diálisis descritas en este artículo, para generar propuestas expositivas que hagan al participante conectar con su cotidianidad y sus experiencias para materializarlas a través del diálogo y el intercambio. Esta actividad comienza a alternarse con propuesta artísticas. 
Un proyecto que arranca ahora y que lleva más de siete meses gestándose. Que ha requerido el acondicionamiento del lugar y la estrecha colaboración del Servicio de atención al paciente en tareas de apoyo y difusión del proyecto. Y que entre otras, requiere la difícil labor de que los potenciales usuarios reparen en que una acción como esta puede ocurrir en el hospital. Cuando lo hacen parecen satisfechos, todos manifiestan poder desconectar del hospital en ese espacio, pero habrá que esperar un tiempo para obtener datos sólidos y más experiencia para encontrar las acciones más adecuadas.
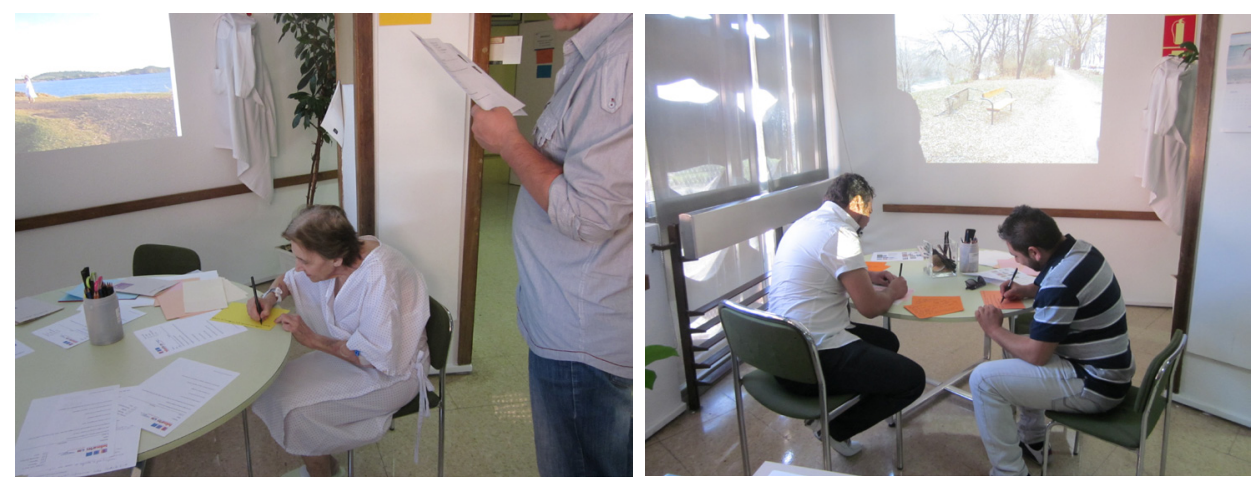

Fig. 21 y 22 Pacientes y acompañantes participando en las reflexiones propuestas por la exposición.

\section{Referencias}

Antúnez, N., Ávila, N., Zapatero, D. 2008: El Arte Contemporáneo en la Educación Artística. Madrid. Ed. Eneida

Borriaud, Nicolas. 2007: Estética Relacional.AH Editora. Buenos Aires.

Corraliza, J.A. 2002: En J.I. Aragonés y M. Amérigo. Psicología Ambiental. Emoción y ambiente. Madrid. Pirámide

G. Cano Marta. 2009: La proyección de Arte Contemporáneo en el hospital como mejora en la humanización del espacio pediátrico y adolescente. Tesina doctoral. Universidad Complutense de Madrid.

McNaughton, Jane. 2007: Art in Hospital Spaces. The role of hospitals in an aestheticized Society. International Journal of Cultural Policy, Vol.13, $\mathrm{N}^{\mathrm{o}} 1$

Ullán, Ana M., Belver, M.H. 2008: Cuando los pacientes son niños. Humanización y calidad en la hospitalización pediátrica. Colección CurArte. Ed. Eneida. Madrid.

Ullán, Ana M. \& Manzanera, P. 2009: Las paredes cuentan. Arte para humanizar un espacio de salud pediátrico. Arte, Individuo y Sociedad, nº21. 123-142 
Nanda, U., Eisen, S.L., Baladandayuthapani, V., 2008: Undertaking an Art Survey to Compare Patient Versus Student Art Preferences. Environment and Behavior 40, 269-301

Nanda, U., Hathorn, K., Chanaud, C. \& Brown, L. 2007:Research on Art for Pediatric Patients. Paper presented at Healthcare Facilities Symposium and Expo. Oct 2-4, 2007. Chicago, IL. 